\title{
High Cks1 expression in transgenic and carcinogen- initiated mammary tumors is not always accompanied by reduction in $\mathbf{p} 27^{\mathrm{Kip} 1}$
}

\author{
LOUISE WESTBROOK ${ }^{1}$, HARISH N. RAMANATHAN ${ }^{1}$, TATYANA ISAYEVA ${ }^{2}$, ANSHU ROY MITTAL ${ }^{1}$, \\ ZHICAN QU $^{1}$, MICHAEL D. JOHNSON ${ }^{3}$, FRANCIS G. KERN ${ }^{1}$, SELVARANGAN PONNAZHAGAN ${ }^{2}$, \\ CLINTON J. GRUBBS ${ }^{2}$ and JAIDEEP V. THOTTASSERY ${ }^{1,2}$
}

\author{
${ }^{1}$ Biochemistry and Molecular Biology Department, Drug Discovery Division, Southern Research Institute, \\ 2000 Ninth Avenue South, Birmingham, AL 35255; ${ }^{2}$ UAB Comprehensive Cancer Center, University of Alabama \\ at Birmingham, Birmingham, AL 35294; ${ }^{3}$ Department of Oncology and Lombardi Comprehensive Cancer Center, \\ Georgetown University Medical Center, 3970 Reservoir Road, NW, Washington, DC 20057, USA
}

Received December 18, 2008; Accepted February 3, 2009

DOI: 10.3892/ijo_00000271

\begin{abstract}
Cks1 plays an essential role in $\mathrm{SCF}^{\mathrm{Skp} 2}$-mediated ubiquitination, and consequently turnover, of the cdk2 inhibitor and tumor supressor p27 ${ }^{\mathrm{Kip} 1}$. High Cks1 expression is associated with aggressive breast tumors and correlates with low $\mathrm{p} 27^{\mathrm{Kip} 1}$ levels in some cases, although it is also an independent prognostic marker for survival, and provides predictive information in addition to that provided by $\mathrm{p} 27^{\mathrm{Kip} 1}$ alone. In this report we demonstrate that Cks1 protein and mRNA are elevated to very high levels in mammary tumors initiated by erbB2, c-myc and polyoma middle-T (PyMT) in transgenic mice, whereas $\mathrm{Cks} 1$ protein is hardly detectable in the normal mammary epithelium. Cks1 is also highly upregulated in rat mammary tumors initiated by methylnitrosourea (MNU). Despite high levels of Cks1 expression, p27 Kip1 levels were not reduced, and were in fact slightly higher in mammary tumors initiated by erbB2, PyMT and MNU. In contrast mammary tumors from MMTV-c-myc mice did exhibit low $\mathrm{p} 27^{\mathrm{Kip} 1}$ and higher levels of Skp2. Together, these data suggest that deregulated Cks1 expression might play roles in oncogene and carcinogen-initiated mammary tumorigenesis independent of p2 $7^{\mathrm{Kip} 1}$ turnover in certain tumors. Stable overexpression of Cks1 in human breast carcinoma MCF-7 cells did not significantly reduce $\mathrm{p} 27^{\mathrm{Kip} 1}$ expression, although it conferred resistance to Faslodex (ICI 182780)-mediated inhibition of colony outgrowth in these cells. In contrast, Cks1-depleted MCF-7 cells formed fewer
\end{abstract}

Correspondence to: Dr Jaideep Thottassery, Biochemistry and Molecular Biology Department, Southern Research Institute, 2000 Ninth Avenue South, Birmingham, AL 35255, USA

E-mail: thottassery@sri.org

Key words: Cks1, mammary tumors, p27 ${ }^{\text {Kip1 }}$, Skp2, myc, polyoma middle-T, estrogen, Faslodex colonies in estrogen-containing medium. Therefore, our studies also suggest that Cks1 levels regulate the responsiveness of $\mathrm{ER}^{+}$breast cancers to estrogens and anti-estrogens.

\section{Introduction}

Cyclin kinase subunit 1 (Cks1) is a small protein whose expression is strongly associated with aggressive breast tumors, prostate carcinomas, non-small cell lung cancers, and several other malignancies (1-4). Cks1 was shown to associate with Skp2, a subunit of the $\mathrm{SCF}^{\mathrm{Skp} 2}$ ubiquitin ligase which mediates the ubiquitin-dependent proteolysis of the cdk inhibitor $p 27^{\text {Kip } 1}$ in $G_{1} / S$-phase $(5,6)$. Skp2 serves as the specificity component for the SCF ${ }^{\text {Skp2 }}$ ligase and binds to $\mathrm{p} 27^{\mathrm{Kip} 1}$ in a manner that depends on $\mathrm{p} 27^{\mathrm{Kip} 1}$ phosphorylation, and on Cks1 (7-9). p27 ${ }^{\mathrm{Kip} 1}$ is also a tumor suppressor protein that works in a dosage-dependent manner $(10,11)$, and analysis of the $\mathrm{Cks}^{-/-}$cells has revealed that depletion of Cks1 increases $\mathrm{p} 27^{\mathrm{Kip} 1}$ protein levels (9). Low levels of the cdk2 inhibitor p2 $7^{\text {Kip } 1}$ have been demonstrated in a number of studies to be associated with reduced overall and disease-free survival in breast cancer patients (12-14). Interestingly however, other studies show that $\mathrm{p} 27^{\mathrm{Kip} 1}$ is overexpressed in a subset of highly proliferative breast carcinomas (15), and this was associated with strong expression of cyclin D1 and ER positivity (16).

Although the role of Cks1 expression in breast cancer, remains to be elucidated, recently Slotky et al have demonstrated that Cks1 expression in human breast cancer was associated with aggressive features and inversely correlated with p27 Kip1 (1). Interestingly, high expression of Cks1 has also been reported in non-small cell lung carcinomas, although it was not inversely related with $\mathrm{p} 27^{\mathrm{Kip} 1}$ expression, suggesting that Cks1 may mediate some of its functions via Skp2 and p27 ${ }^{\text {Kipl} 1-i n d e p e n d e n t ~ m e c h a n i s m s ~(3) . ~ R e c e n t ~ g l o b a l ~ e x p r e s s i o n ~}$ profiling experiments have also shown high levels of Cks1 mRNA in mammary tumors from the polyoma middle-T (PyMT)-initiated transgenic model (17). Thus, deregulation of Cks1 expression is likely to be an important hallmark of 
mammary transformation. However, whether Cks1 protein levels are also induced, and whether p27 ${ }^{\mathrm{Kip} 1}$ levels are also altered in concert, have not been evaluated in these or other models of mammary tumorigenesis. In this report we show that Cks1 protein is highly elevated in mammary carcinomas initiated by the PyMT oncogene in a bitransgenic mouse model. High Cks1 was, however, not associated with decreased p2 $7^{\text {Kip } 1}$. Instead p27 ${ }^{\text {Kip } 1}$ levels were higher in these tumors, and were accompanied by decreased Skp2 expression as well. Similarly we also found that $\mathrm{Cks} 1$ was also highly elevated in tumors initiated by erbB2, c-Myc, and the carcinogen MNU. However, p27 ${ }^{\text {Kip1 }}$ levels were reduced only in c-Myc initiated tumors. We also assessed the role of $\mathrm{Cks} 1$ in estradiol $\left(\mathrm{E}_{2}\right)$ dependent pathways in a MCF-7 derived $\mathrm{ER}^{+}$breast carcinoma line. We demonstrate that forced ectopic Cks1 expression in these cells confers substantial resistance to the anti-estrogen ICI 182780, although it did not substantially alter p27 ${ }^{\text {Kip } 1}$ levels. In contrast shRNA-mediated depletion of Cks1 in MCF-7 markedly diminished colony formation in estrogen-containing complete medium.

\section{Materials and methods}

Materials and chemicals. ICI 182780 (Faslodex ${ }^{\circledR}$ ) was a gift from AstraZeneca (Macclesfield, Cheshire, UK) and was dissolved in ethanol prior to use. Improved modified Eagle's medium (IMEM) medium was obtained from Mediatech (Manassas, VA).

Mammary tumors from transgenic mouse models. Murine mammary tumors used in these studies were obtained from three separate models. A bitransgenic mouse model established in our laboratory harbors the tet-transactivator rtTA transgene which is under control of the C3(1) 5' flanking region derived from the $\mathrm{C} 3(1)$ component of prostatic steroid binding protein (PSBP) (Thottassery JV, et al, Proc Am Assoc Cancer Res 42: abs. 913, 2001). In addition these mice have a tetracycline response element (TRE) regulated $1.4 \mathrm{~kb}$ sequence encoding the PyMT protein. Mammary tumors were excised from females that were given Dox in the drinking water from 80 to 120 days. MMTV-ErbB2 female mice were obtained from the laboratory of Dr Mike Ruppert (UAB) and mammary tumors, and uninvolved mammary glands, were excised from these mice. MMTV-c-Myc mice have been described before (18). All mice were housed and cared for in AAALACaccredited facilities in accordance with guidelines established by the NIH.

Mammary tumors from MNU-treated rats. Methylnitrosourea (75 mg/kg BW) was administered via the jugular vein to a female Sprague-Dawley rat at 50 days of age. Mammary tumors were removed at 93 days after carcinogen treatment.

Cksl shRNA plasmid construction and colony formation studies. To construct a shRNA expression vector targeting Cks1 we used a U6-promoter containing expression plasmid called pSub201-U6.1/Neo previously derived from the plasmid pRNAT-U6.1/Neo (from GenScript, Piscataway, NJ). The vector contains a G418 resistance marker which facilitates enforced expression of the shRNA. Two oligonucleotides with BamHI and HindIII cohesive ends targeting a sequence in Cks1 were generated. The sequence of the top strand was: 5'-GATCCTCT GATGTCTGAATCTGAATT TTCAAGA GAAATTCA GATTCAGACATCAGA TTTTTA. The sequence incorporates a 21-bp sense and antisense strand flanking a 9-bp hairpin loop (underlined). The top and bottom strand oligonucleotides were annealed, phosphorylated and ligated into the pSub201-U6.1/Neo vector.

Colony formation studies were done with this plasmid, and the parental control plasmid to examine whether depletion of Cks1 in MCF-7 breast carcinoma cells will affect their ability to form colonies in G418-medium containing $10 \%$ FBS. We used $10 \%$ FBS because it contains the full estrogen complement (estradiol, estriol and estrone). MCF-7 cells $\left(2 \times 10^{5}\right)$ were transfected with the pSub201-U6.1/Neo control plasmid or the pSub201-U6.1/Neo-Cks1 shRNA plasmid using Fugene HD (Roche) and were then exposed to G418 (1 mg/ml) in $10 \% \mathrm{FBS}$ containing medium. Colonies formed were fixed and stained by incubation with $0.05 \%$ crystal violet, washed with deionized water and photographed.

Cks 1 expression plasmid construction and stable transfections. To test whether overexpressing Cks1 can affect the inhibition of $\mathrm{ER}^{+}$breast cancer cell growth by anti-estrogens we constructed an expression plasmid for Cks1 driven by the strong CMV promoter called pIIB-CMV-Cks1. This plasmid contains a synthetic intron and a tandemly linked internal ribosome entry site (IRES) downstream from the full length Cks1 cDNA. This is followed by a blasticidin resistance marker (bsdR). MCF-7 cells $\left(1.2 \times 10^{6}\right)$ were plated in $10-\mathrm{cm}$ tissue culture dishes and were transfected the next day either with pIIB-CMV-Cks1 or the empty vector pIIB-CMV. The cells were then exposed to blasticidin $(3 \mu \mathrm{g} / \mathrm{ml})$ and drug-resistant pools were isolated.

Cells $\left(3 \times 10^{4}\right)$ of stable polyclonal populations of $\mathrm{pIIB}$ CMV-Cks1 or pIIB-CMV transfectants were plated in 6-well dishes in $5 \%$ FBS containing medium and exposed to increasing doses of ICI 182780 for 2 weeks in the presence of blasticidin. The medium was changed every 5 days. Colonies formed were fixed and stained by incubation with $0.05 \%$ crystal violet, washed with deionized water and photographed. Colonies were counted using a Scienceware ${ }^{\circledR}$ colony counter (Bel-Art Products, Pequannock, NJ).

Western immunoblotting. For the analysis of Cks1, Skp2, p27 ${ }^{\mathrm{Kip} 1}$ etc., Western immunoblotting was performed on lysates prepared from mammary tumors or MCF-7 transfectant pools. In general, $40 \mu \mathrm{g}$ of cell lysate was run on Criterion ${ }^{\circledR}$ pre-cast $10 \%$ SDS-PAGE gels (Bio-Rad, Hercules, CA). Proteins were transferred onto Protran ${ }^{\circledR}$ filters (Bio-Rad, Hercules, CA) by electroblotting and blots were probed with antibodies. Enhanced chemiluminescence detection with the Supersignal West Pico kit was used (Pierce, Rockford, IL).

QRT-PCR analysis of Cksl in mammary tumors. To compare the levels of Cks1 mRNA in mammary tumors versus normal mammary tissue from transgenic mice a qRT-PCR approach was used. Total RNA was made from snap-frozen excised tumor fragments and the quality of the RNA was assessed on agarose gels prior to running the RT-PCR reactions. Murine 


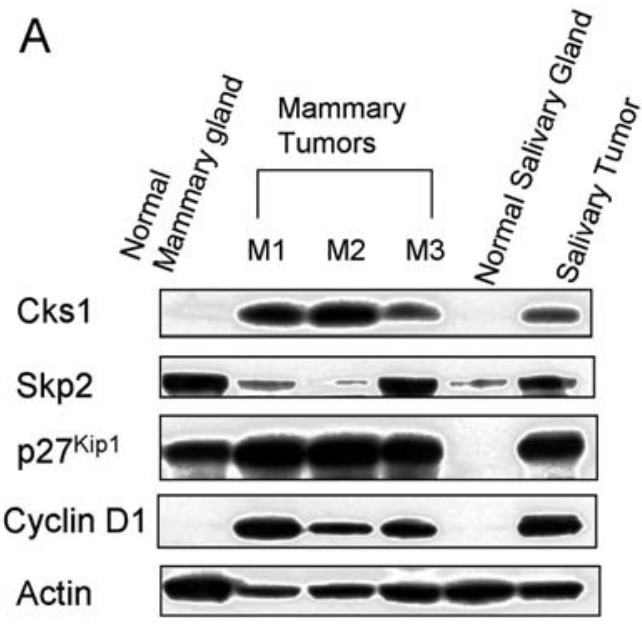

B

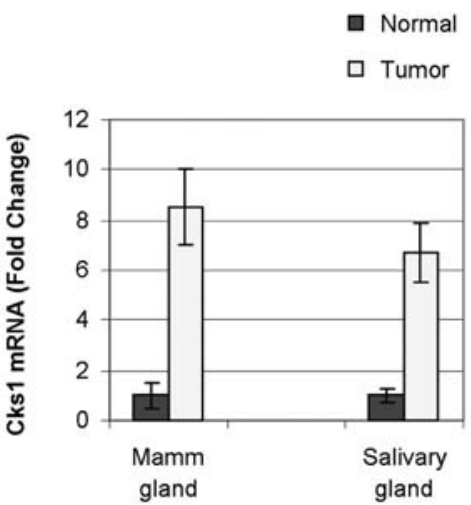

Figure 1. Cks1 is highly expressed in PyMT-initiated mammary adenocarcinomas in bitransgenic mice. A, Mice were given Dox in their drinking water to induce PyMT for 80-120 days and mammary tumors were excised. Protein extracts from mammary and salivary tumors and uninvolved mammary and salivary glands were run on SDS-PAGE gels and were transferred to nitrocellulose membranes and analyzed by immunoblotting with antibodies against Cks1, Skp2, p27 ${ }^{\mathrm{Kip} 1}$, cyclin D1 and actin. B, QRT-PCR analysis of Cks1 specific transcripts in mammary tumors and salivary tumors from bitransgenic mice. Total RNA was made and analyzed by qRT-PCR as described in Materials and methods.
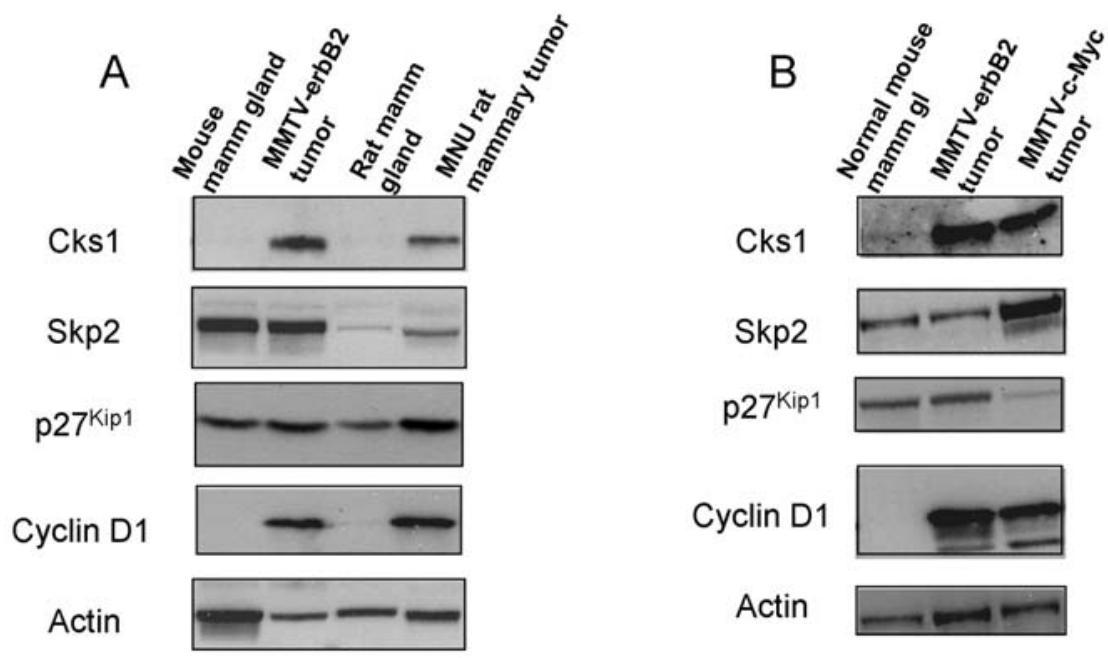

Figure 2. Cks1 is highly expressed in erbB2 and in c-Myc-initiated mammary adenocarcinomas. Cks1 expression is also induced in MNU-initiated rat mammary carcinomas. Protein extracts from mammary tumors and normal glands from MMTV-erbB2 mice and rats treated with MNU (75 mg/kg), A and B, and from MMTV-c-Myc mice; B, were run on SDS-PAGE gels and were transferred to nitrocellulose membranes and analyzed by immunoblotting with antibodies against Cks1, Skp2, p2 $7^{\mathrm{Kip} 1}$, cyclin D1 and actin.

Cks1 specific TaqMan primer-probe sets were obtained (Applied Biosystems). Reactions were carried out in an MJ Cycler using the Opticon monitor software. The comparative $\mathrm{C}_{\mathrm{T}}$ method was used to represent the relative level of either Cks1 transcripts. The relative expression level is expressed as a unitless number and calculated as $2^{-\Delta \Delta \mathrm{T}}$ as previously described (19).

\section{Results}

Cks1 protein and $m R N A$ are overexpressed in murine transgenic models of mammary tumorigenesis. We have established a bitransgenic mouse model where the mammary expression of PyMT can be controlled by providing doxycycline (Dox) in the drinking water. These mice harbor two transgenes, a C3(1) promoter driven reverse tet-transactivator (rtTA) and a tetracycline response element (TRE) controlled PyMT. The transforming ability of PyMT is related to its ability to bind and activate signal transduction proteins that have been implicated in human breast cancer $(20,21)$. Importantly, PyMTinitiated mammary tumors have recently been shown to be $\mathrm{ER}^{+}$and demonstrate estrogen-dependent growth in vivo and also in vitro in cells from explants $(22,23)$.

Loss of $\mathrm{p} 27^{\mathrm{Kip} 1}$ has been demonstrated to enhance the rate of onset of erbB2 induced mammary tumorigenesis in transgenic mice and reduced $\mathrm{p} 27^{\mathrm{Kip} 1}$ expression is frequently detected in many human cancers, including breast cancers $(24,25)$. Since $\mathrm{p} 27^{\mathrm{Kip} 1}$ levels are primarily regulated by its ubiquitination by the $\mathrm{SCF}^{\mathrm{Skp} 2}$ ubiquitin ligase and subsequent proteolysis, we assessed the levels of $\mathrm{p} 27^{\mathrm{Kip} 1}$, Skp2 and Cks1 in mammary carcinomas initiated by PyMT in our bitransgenic mouse model. Interestingly, we find that $\mathrm{p} 27^{\mathrm{Kip} 1}$ levels are not reduced, but are instead induced, reproducibly, in PyMT-initiated tumors (Fig. 1A). We also found that Skp2 levels were reduced in some of these tumors relative to the 
A
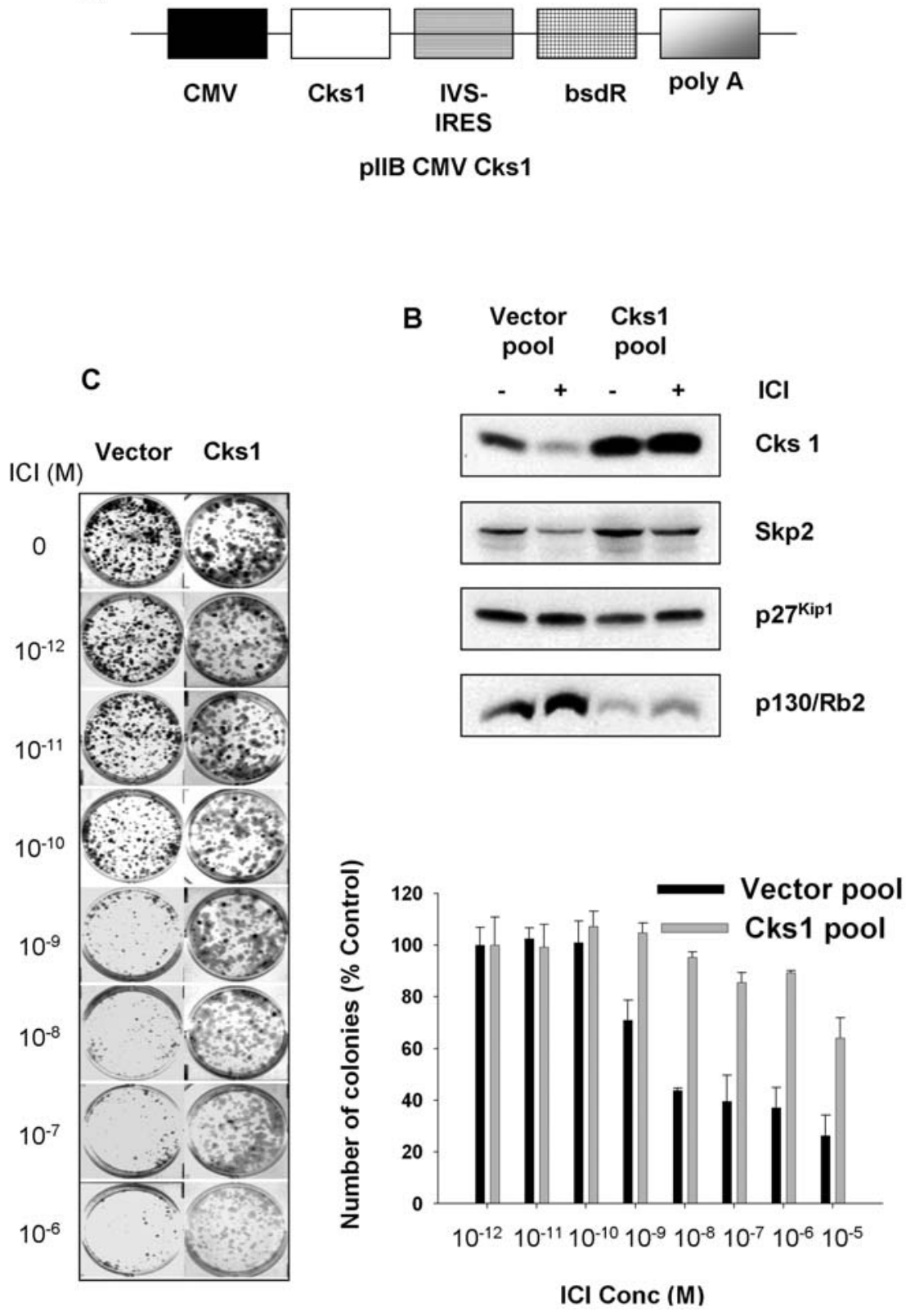

Figure 3. Stable overexpression of Cks1 in MCF-7 breast carcinoma cells decreases p130/Rb2 levels and causes anti-estrogen resistant colony formation. A, Schematic of the expression vector pIIB-CMV-Cks1 that was stably transfected into MCF-7 cells to generate polyclonal pools overexpressing Cks1. B, ICI 182780 mediated up-regulation of p130/Rb2 occurs in vector-transfected pools of MCF-7 cells but is decreased in stably transfected cells overexpressing Cks1. C, Dose response of ICI 182780 effects on colony formation in Cks1 overexpressing pools versus vector-transfected control MCF-7 cells. $3 \times 10^{4}$ cells from each line were plated in 6-well dishes and subsequently treated over two weeks with the indicated concentrations of ICI 182780. The colonies were the fixed, stained, counted and photographed as described in Materials and methods. Means \pm SD of three experiments are graphically represented.

normal mammary gland (Fig. 1A). Cyclin D1 levels were also greatly elevated in mammary tumors. Most remarkably Cks1 levels were markedly enhanced in these tumors, unlike Skp2, suggesting that Cks1 plays a role in mammary oncogenic pathways, possibly through Skp2-independent mechanisms (Fig. 1A). Cks1 protein levels, on the other hand, were minimal in the normal mammary gland unlike Skp2 (Fig. 1A). To assess the relative expression of Cks1 mRNA in tumors versus the normal gland we performed a qRT-PCR assay. As shown in Fig. 1B, the increases in immunodetectable Cks protein in the mammary tumors were accounted for by increases in Cks1 mRNA. The PyMT-transgenic mice also exhibit salivary gland tumors and likewise we also found highly elevated Cks1 protein and mRNA in salivary gland tumors as compared to the normal gland. The normal salivary gland does not have detectable $\mathrm{p} 27^{\mathrm{Kip} 1}$ protein, although p2 ${ }^{\mathrm{Kip} 1}$ was greatly elevated in salivary tumors.

We also examined whether the increases in Cks1 exhibited by mammary tumors initiated by the PyMT oncogene could be generalized to other initiating agents by doing Western analyses with lysates obtained from tumors excised out of MMTV-erbB2 and MMTV-c-Myc mice, and also from tumors formed in rats treated with the carcinogen MNU. As shown in Fig. 2, Cks1 protein was elevated in all of these tumors. Once again p27 ${ }^{\mathrm{Kip} 1}$ was slightly elevated in tumors from the MMTV-erbB2 model and the MNU-treated rats (Fig. 2A). 
However, p27 $7^{\text {Kip } 1}$ levels were lower in tumors from the MMTVc-Myc mice as compared to the normal gland, and interestingly these mice also had elevated Skp2 levels (Fig. 2B). Cyclin D1 levels were highly upregulated in all three tumor models.

Ectopic Cks1 overexpression causes a decrease in basal and ICI 182780-induced p130/Rb2 levels and also induces ICI 182780-resistant colony formation. To address whether Cks1 overexpression might alter $\mathrm{p} 27^{\mathrm{Kip} 1}$ and thereby decrease responsiveness to anti-estrogens in human breast cancer, a MCF-7 line that constitutively overexpresses Cks1 was established. An expression vector that enforces Cks1 expression by use of an IRES-coupled antibiotic resistance marker was employed (Fig. 3A). To avoid effects due to clonal variation, polyclonal populations of cells stably transfected with this expression vector or the empty vector were isolated. Both the vector pool and the Cks1 overexpressing pool were first characterized with respect to Cks1 expression, and also expression of Skp2, p27 Kip1 and p130/Rb2. As shown in Fig. 3B, ectopic Cks1 expression was high in the Cks1 pool as determined with the anti-Cks1 antibody. A 72-h treatment with ICI 182780 markedly decreases Cks1 in the vector pool but not in the Cks1 transfectants (Fig. 3B and data not shown). Skp2 levels under basal and ICI 182780 treated conditions were slightly higher in the Cks1 pool, and consistently p130/Rb2 levels were markedly decreased in the Cks1 pool under both conditions. However, p2 $7^{\mathrm{Kip} 1}$ was only marginally decreased in the Cks1 pool relative to the vector pool. Levels of p27 $7^{\text {Kip } 1}$ increased somewhat upon ICI 182780 treatment, although they did not reach the levels in ICI 182780-treated vector-transfected cells (Fig. 3B).

We also performed a clonogenic assay with increasing doses of ICI 182780 to assess the effects of Cks1 overexpression on anti-estrogen effects in long-term growth. As shown in Fig. 3C, ICI 182780 decreased colony formation in both vector transfectants as well as Cks1 transfectants, although higher doses were required for equivalent suppression of clonogenicity in the Cks1 overexpressors. We also found that following a 72-h treatment of the vector-transfected pool with ICI 182780 the proportion of cells in $\mathrm{G}_{1} / \mathrm{G}_{0}$-phase increased from $52.73 \pm 3.19$ to $81.06 \pm 1.96$. On the other hand, a 72 -h treatment of the Cks1 overexpressing pool with the antiestrogen only resulted in an increase in the $G_{1} / G_{0}$-phase from $54 \pm 1.7$ to $65.2 \pm 1.07(\mathrm{P}<0.05)$.

shRNA-mediated Cksl depletion in MCF-7 breast carcinoma cells abrogates colony formation in estrogen-containing medium. MCF-7 cells are $\mathrm{ER}^{+}$breast carcinoma cells that require estrogens in the medium for robust colony formation. Our previously published studies have demonstrated that Cks1 contributes to multiple essential roles during cell cycle progression in MCF-7 cells (26). In the current study we tested whether Cks1 abrogation could affect MCF-7 colony formation in complete medium. Since long-term colonyforming studies cannot be carried out with cells transfected with siRNA duplexes we constructed a Cks1 shRNA expression vector containing a G418 marker. Selection in G418-containing complete medium showed that Cks1 depleted cells formed significantly fewer colonies than the control vector transfected cells (Fig. 4A). We also performed Western
A

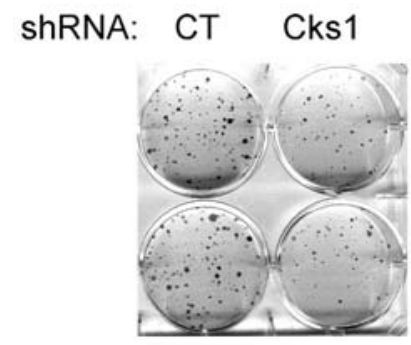

B

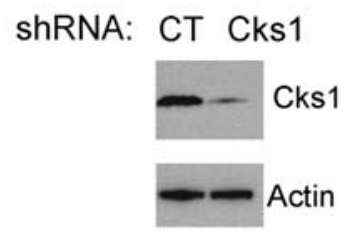

Figure 4. Depletion of Cks1 in MCF-7 breast carcinoma cells abrogates colony formation in estrogen-containing medium. A, MCF-7 breast carcinoma cells were transfected with the pSub201-U6.1/Neo control plasmid or the pSub201U6.1/Neo-Cks1 shRNA plasmid using Fugene HD (Roche) and were then exposed to G418 (1 mg/ml) in 10\% FBS containing medium. Colonies formed were fixed, stained and photographed. B, Protein extracts from G418-resistant colonies were run on SDS-PAGE gels, transferred to nitrocellulose membranes and analyzed by immunoblotting with antibodies against Cks1 and actin.

analyses with the remaining colonies in the Cks1-shRNA transfected population (Fig. 4B). The results show that remnant colony outgrowth in the Cks1-shRNA transfected population occurs probably because Cks1, although substantially reduced, was not completed depleted in these cells. This could be either because the U6 promoter does not drive expression of Cks1 shRNA strongly, or the expressed sequence was not very efficient in completely silencing Cks1 in these cells.

\section{Discussion}

In this report we have shown that Cks1 protein and mRNA are highly elevated in murine mammary tumors initiated by the oncogenes erbB2, c-Myc or PyMT, and in a carcinogeninitiated rat mammary tumor model, suggesting that deregulated Cks1 expression might play an important role in mammary epithelial transformation by these agents. Cks proteins were originally identified as suppressors of mutations in the yeast cdk1 genes p34 $4^{\mathrm{cdc} 2}$ and $\mathrm{p} 36^{\mathrm{cdc} 28}(27-29)$. The $S$. cerevisiae $\mathrm{Cks} 1$ gene and its $S$. pombe homolog p13 ${ }^{\text {Suc1 }}$ were both shown to be physically associated with cdk 1 and with active cyclin-cdk1 complexes (29). However, the biochemical functions of Cks1 had remained elusive until the recent demonstration by different groups that it played an essential role in $\mathrm{p} 27^{\mathrm{Kip} 1}$ degradation, by promoting the interaction of Skp2 with $\mathrm{p} 27^{\mathrm{Kip} 1}$, and facilitating its ubiquitylation $(8,9)$. Previous studies have implicated $\mathrm{p} 27^{\mathrm{Kip} 1}$ as an inhibitor of erbB2 signalling (30). These studies have also suggested that c-Myc functions by abrogating the function of $\mathrm{p} 27^{\mathrm{Kip} 1}$ (30). Studies have also implicated that $\mathrm{p} 27^{\mathrm{Kip} 1}$ might be a tumor suppressor (31). However, it is rarely mutated in cancers and $\mathrm{p} 27^{-/-}$mice do not show enhanced spontaneous tumor onset with the exception of pituitary adenomas (11). The $\mathrm{p} 27^{+/-}$ 
mice do exhibit multiple tumors when challenged with radiation or carcinogens. In these tumors $\mathrm{p} 27^{\mathrm{Kip} 1}$ is neither mutated nor silenced and therefore it is considered a haploinsufficient tumor suppressor.

Increases in Cks 1 expression have been shown in a number of human malignancies (1-4). Increase in Cks1 mRNA has also been shown in PyMT-initiated mammary tumors (17), and in urethane and ENU-initiated lung tumors in rasH2 mice (32). Although it has generally been implied that the role of Cks1 in transformation is related to its essential role in p27 $7^{\text {Kip1 }}$ degradation our studies suggest that this is not necessarily the case in all tumors. Indeed, our studies suggest that $\mathrm{p} 27^{\mathrm{Kip} 1}$ levels were in fact slightly higher in mammary tumors initiated by erbB2, PyMT and MNU. This apparent discrepancy could be reconciled by recognizing that in addition to its cdk2inhibitory effects, p27 $7^{\mathrm{Kip} 1}$ also functions as an assembly factor for cyclin D/cdk 4/6 complexes, thereby activating cyclin D1 dependent kinases (33). Therefore, the coordinate upregulation of cyclin D1 and p27 $7^{\mathrm{Kip} 1}$ seen in these models could play an important role in mammary epithelial transformation by stimulating proliferative signaling induced by cyclin D1 dependent kinases.

What then could be the molecular consequences of $\mathrm{Cks} 1$ protein elevations during mammary transformation? Cks proteins also have roles in stimulating the phosphorylations of $\mathrm{G}_{2} / \mathrm{M}$ regulators such as cdc 2 kinases Wee1 and Myt 1 and also the phosphatase Cdc25 (34). Cdc25 mediated dephosphorylation has also been shown to play a crucial role in Cdk2 activation. Thus, it is possible that Cks1 also has other roles in $\mathrm{G}_{1}$ distinct from its role as an adaptor molecule that facilitates substrate recruitment to the $\mathrm{SCF}^{\mathrm{Sk} 2}$ complex in $\mathrm{p} 27^{\mathrm{Kip} 1} \mathrm{de}-$ gradation. In this respect it is also important to note that Deshaies and co-workers have shown that Cks1 plays an essential role in $\mathrm{G}_{1}$ cyclin Cdk activity in yeast (35). Previously published results from our laboratory have also demonstrated a role for Cks1 in the expression of cdc2 (26). The binding of cyclin B to Cdk1 and cyclin A to Cdk2 has also been shown to enhance $\mathrm{Cdk}$ binding to $\mathrm{Cks} 2$ suggesting that cyclins and Cks proteins interact cooperatively with Cdks (36). In addition, Cks proteins have stimulatory effects on the $\mathrm{Cdc} 27$ component of anaphase promoting complex/cyclosome (APC/C) complex, another ubiquitin ligase that degrades mitotic regulators such as cyclin B and securin $(34,37,38)$. Recently Cks1 was also shown to increase the transcription of $\mathrm{Cdc} 20$, a protein which activates $\mathrm{APC} / \mathrm{C}$ by targeting it to distinct substrates to allow cells to exit from mitosis (39). Therefore Cks1 could likely play important roles in mammary epithelial transformation by regulating any number of important cell cycle processes.

Our previously published results also demonstrated that Cks1 regulates both $\mathrm{p} 27^{\mathrm{Kip} 1}$ and $\mathrm{p} 130 / \mathrm{Rb} 2$ in MCF-7 cells (26). In this study we assessed whether Cks1 overexpression in these cells would alter their response to anti-estrogens through its effects on these cdk2 inhibitors. We demonstrate that overexpression of Cks1 in these cells induced substantial resistance to Faslodex in a clonogenic assay (Fig. 3). However, the effects of Cks1 overexpression on p27 ${ }^{\mathrm{Kip} 1}$ levels in the MCF-7 line are relatively modest, despite the fact that $\mathrm{Cks} 1$ transfectants exhibit decreased $\mathrm{G}_{1} / \mathrm{G}_{0}$ arrest in Faslodex. Instead we demonstrate that steady-state levels of $\mathrm{p} 130 / \mathrm{Rb} 2$ in basal conditions, and also its levels in ICI 182780-treated cells were much lower in Cks1 overexpressors (Fig. 3). This is consistent with the findings of Reed and colleagues who showed that transduction of $\mathrm{Cks}^{-/}$fibroblasts with $\mathrm{Cks} 1$ expressing recombinant adenovirus decreased $\mathrm{p} 130 / \mathrm{Rb} 2$ to wild-type levels (40). In addition, we demonstrate that Cks1 overexpression resulted in a small but reproducible increase in Skp2 levels in these cells. Cks1 has been shown to prevent Skp2 autoubiqitination by the SCF complex, thereby increasing its stability (41). This suggests a scenario wherein upregulation in $\mathrm{Cks} 1$ during $\mathrm{G}_{1} / \mathrm{S}$ progression results in coordinated increases in Skp2 expression as well, which may be required for sufficient down-regulation of p130/Rb2 and consequent cyclin-cdk2 activation. Skp2 overexpression in the $\mathrm{ER}^{+}$line MCF-7 also leads to an acute resistance to the effects of tamoxifen and ICI 182780 on the cell cycle, respectively (42). However, although the role of Skp2 in endocrine therapy failure has not been formally tested, higher Skp2 expression has been demonstrated to be less frequent in $\mathrm{ER}^{+}$versus ER- breast tumors in a microarray study (43).

It is not clear why overexpression of $\mathrm{Cks} 1$ causes a selective decrease in the steady state levels of $\mathrm{p} 130 / \mathrm{Rb} 2$, without significantly affecting p27 Kip1 levels in MCF-7 cells. Down-regulation of $\mathrm{p} 27^{\mathrm{Kip} 1}$ can also occur by its re-localization to cytoplasm following its prior phosphorylation on Ser10, Thr157 or Thr198 by various signaling cascades $(44,45)$. A recent study comparing several breast cancer lines had concluded that $\mathrm{ER}^{+}$lines like MCF-7 and ZR75 express relatively higher levels of p27 $7^{\mathrm{Kip} 1}$ (15). Interestingly, these lines also contain relatively high levels of cyclin D1 and cdk4. Therefore, it is likely that the primary model of downregulation of $\mathrm{p} 27^{\mathrm{Kip} 1}$ inhibitory activity towards cyclin-cdk2 is via its relocalization and its sequestration by cyclin DCdk4/6 complexes rather than its proteolytic degradation in this system.

In conclusion, our data suggest that Cks1 elevation could play important roles in mammary transformation induced by multiple oncogenic or carcinogenic agents. Our data also suggest that in $\mathrm{ER}^{+}$breast cancers $\mathrm{Cks} 1$ might play an important role in both estrogen-stimulated and anti-estrogen resistant progression. In addition to being essential in the

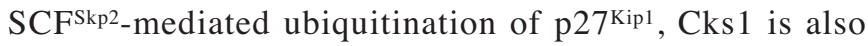
essential in the degradation of $\mathrm{p} 130 / \mathrm{Rb} 2$, another cdk2 inhibitor whose degradation is also mediated by $\mathrm{SCF}^{\mathrm{Skp} 2}$ (40). In addition to its cdk2 inhibitory function, p130/Rb2 also appears to mediate its anti-proliferative effects by E2F-dependent inhibition of transcription through the formation of suppressor complexes with the E2F factors E2F4 and E2F5 (46). The p130/Rb2 protein is abundant in $G_{0}$ and in early $G_{1}$ and a distinguishing feature of cell cycle arrest induced by the antiestrogen ICI 182780 in ER + MCF-7 breast cancer cells is that the cells are arrested in $\mathrm{G}_{0}$-like quiescent state characterized by accumulation of $\mathrm{p} 130 / \mathrm{Rb} 2$ (47). Thus, in addition to being a potential mammary oncogene Cks1 could also likely promote anti-estrogen resistant progression in breast cancers by abrogating the effects of $\mathrm{p} 130 / \mathrm{Rb} 2$.

\section{Acknowledgements}

The work was supported in part by Susan G. Komen Breast Cancer Foundation grants BCTR-000456 (J.V.T.) and 
BCTR-50206 (S.P.). J.V.T. is also supported by the Adolph Weil Endowment at Southern Research Institute.

\section{References}

1. Slotky M, Shapira M, Ben-Izhak O, et al: The expression of the ubiquitin ligase subunit $\mathrm{Cks} 1$ in human breast cancer. Breast Cancer Res 7: R737-R744, 2005.

2. Lan Y, Zhang Y, Wang J, et al: Aberrant expression of Cks1 and Cks2 contributes to prostate tumorigenesis by promoting proliferation and inhibiting programmed cell death. Int J Cancer 123: 543-551, 2008

3. Inui N, Kitagawa K, Miwa S, et al: High expression of Cks1 in human non-small cell lung carcinomas. Biochem Biophys Res Commun 303: 978-984, 2003

4. Shapira M, Ben-Izhak O, Linn S, et al: The prognostic impact of the ubiquitin ligase subunits Skp2 and Cks1 in colorectal carcinoma. Cancer 103: 1336-1346, 2005.

5. Pagano M, Tam SW, Theodoras AM, et al: Role of the ubiquitinproteasome pathway in regulating abundance of the cyclindependent kinase inhibitor p27. Science 269: 682-685, 1995.

6. Carrano AC, Eytan E, Hershko A and Pagano M: SKP2 is required for ubiquitin-mediated degradation of the CDK inhibitor p27. Nat Cell Biol 1: 193-199, 1999.

7. Carrano AC and Pagano M: Role of the F-box protein Skp2 in adhesion-dependent cell cycle progression. J Cell Biol 153: 1381-1390, 2001.

8. Ganoth D, Bornstein G, Ko TK, et al: The cell-cycle regulatory protein $\mathrm{Cks} 1$ is required for $\mathrm{SCF}(\mathrm{Skp} 2)$-mediated ubiquitinylation of p27. Nat Cell Biol 3: 321-324, 2001.

9. Spruck C, Strohmaier H, Watson M, et al: A CDK-independent function of mammalian Cks1: targeting of $\mathrm{SCF}(\mathrm{Skp} 2)$ to the CDK inhibitor p27Kip1. Mol Cell 7: 639-650, 2001.

10. Fero ML, Rivkin M, Tasch M, et al: A syndrome of multiorgan hyperplasia with features of gigantism, tumorigenesis, and female sterility in p27(Kip1)-deficient mice. Cell 85: 733-744, 1996.

11. Fero ML, Randel E, Gurley KE, et al: The murine gene p27Kip1 is haplo-insufficient for tumour suppression. Nature 396: 177-180, 1998.

12. Catzavelos C, Bhattacharya N, Ung YC, et al: Decreased levels of the cell-cycle inhibitor p27Kip1 protein: prognostic implications in primary breast cancer. Nat Med 3: 227-230, 1997.

13. Porter PL, Malone KE, Heagerty PJ, et al: Expression of cellcycle regulators p27Kip1 and cyclin E, alone and in combination, correlate with survival in young breast cancer patients. Nat Med 3: 222-225, 1997.

14. Tan P, Cady B, Wanner M, et al: The cell cycle inhibitor $\mathrm{p} 27$ is an independent prognostic marker in small (T1a,b) invasive breast carcinomas. Cancer Res 57: 1259-1263, 1997.

15. Fredersdorf S, Burns J, Milne AM, et al: High level expression of p27(kip1) and cyclin D1 in some human breast cancer cells: inverse correlation between the expression of p27(kip1) and degree of malignancy in human breast and colorectal cancers. Proc Natl Acad Sci USA 94: 6380-6385, 1997.

16. Barnes DM and Gillett CE: Cyclin D1 in breast cancer. Breast Cancer Res Treat 52: 1-15, 1998.

17. Qiu TH, Chandramouli GV, Hunter KW, et al: Global expression profiling identifies signatures of tumor virulence in MMTV PyMT-transgenic mice: correlation to human disease. Cancer Res 64: 5973-5981, 2004.

18. Jamerson MH, Johnson MD and Dickson RB: Of mice and Myc: c-Myc and mammary tumorigenesis. J Mammary Gland Biol Neoplasia 9: 27-37, 2004.

19. Pfaffl MW: A new mathematical model for relative quantification in real-time RT-PCR. Nucleic Acids Res 29: e45, 2001.

20. Guy CT, Muthuswamy SK, Cardiff RD, et al: Activation of the $\mathrm{c}$-Src tyrosine kinase is required for the induction of mammary tumors in transgenic mice. Genes Dev 8: 23-32, 1994.

21. Webster MA, Hutchinson JN, Rauh MJ, et al: Requirement for both She and phosphatidylinositol 3' kinase signaling pathways in polyomavirus middle T-mediated mammary tumorigenesis. Mol Cell Biol 18: 2344-2359, 1998.

22. Maglione JE, Moghanaki D, Young LJ, et al: Transgenic polyoma middle-T mice model premalignant mammary disease. Cancer Res 61: 8298-8305, 2001.

23. Dabrosin C, Palmer K, Muller WJ and Gauldie J: Estradiol promotes growth and angiogenesis in polyoma middle $\mathrm{T}$ transgenic mouse mammary tumor explants. Breast Cancer Res Treat 78: 1-6, 2003.
24. Hulit J, Lee RJ, Russell RG and Pestell RG: ErbB-2-induced mammary tumor growth: the role of cyclin D1 and p27Kip1. Biochem Pharmacol 64: 827-836, 2002.

25. Bloom J and Pagano M: Deregulated degradation of the cdk inhibitor p27 and malignant transformation. Semin Cancer Biol 13: 41-47, 2003.

26. Westbrook L, Manuvakhova M, Kern FG, et al: Cks1 regulates cdk1 expression: a novel role during mitotic entry in breast cancer cells. Cancer Res 67: 11393-11401, 2007.

27. Hayles J, Beach D, Durkacz B and Nurse P: The fission yeast cell cycle control gene cdc2: isolation of a sequence suc1 that suppresses cdc2 mutant function. Mol Gen Genet 202: 291-293, 1986.

28. Hadwiger JA, Wittenberg C, Mendenhall MD and Reed SI: The Saccharomyces cerevisiae CKS1 gene, a homolog of the Schizosaccharomyces pombe suc1+ gene, encodes a subunit of the Cdc28 protein kinase complex. Mol Cell Biol 9: 2034-2041, 1989.

29. Brizuela L, Draetta G and Beach D: p13suc1 acts in the fission yeast cell division cycle as a component of the $\mathrm{p} 34 \mathrm{cdc} 2$ protein kinase. EMBO J 6: 3507-3514, 1987.

30. Neve RM, Sutterluty H, Pullen N, et al: Effects of oncogenic ErbB2 on G1 cell cycle regulators in breast tumour cells. Oncogene 19: 1647-1656, 2000.

31. Slingerland J and Pagano M: Regulation of the cdk inhibitor p27 and its deregulation in cancer. J Cell Physiol 183: 10-17, 2000.

32. Okamura M, Unami A, Moto M, et al: The possible mechanism of enhanced carcinogenesis induced by genotoxic carcinogens in rasH2 mice. Cancer Lett 245: 321-330, 2007.

33. Cheng M, Olivier P, Diehl JA, et al: The p21(Cip1) and p27(Kip1) CDK 'inhibitors' are essential activators of cyclin D-dependent kinases in murine fibroblasts. EMBO J 18: 1571-1583, 1999.

34. Patra D, Wang SX, Kumagai A and Dunphy WG: The xenopus Suc1/Cks protein promotes the phosphorylation of $\mathrm{G}(2) / \mathrm{M}$ regulators. J Biol Chem 274: 36839-36842, 1999.

35. Reynard GJ, Reynolds W, Verma R and Deshaies RJ: Cks1 is required for $\mathrm{G}(1)$ cyclin-cyclin-dependent kinase activity in budding yeast. Mol Cell Biol 20: 5858-5864, 2000.

36. Egan EA and Solomon MJ: Cyclin-stimulated binding of Cks proteins to cyclin-dependent kinases. Mol Cell Biol 18: 3659-3667, 1998.

37. Patra D and Dunphy WG: Xe-p9, a Xenopus Suc1/Cks protein, is essential for the Cdc2-dependent phosphorylation of the anaphase-promoting complex at mitosis. Genes Dev 12: 2549-2559, 1998.

38. Patra D and Dunphy WG: Xe-p9, a Xenopus Suc1/Cks homolog, has multiple essential roles in cell cycle control. Genes Dev 10: $1503-1515,1996$

39. Morris MC, Kaiser P, Rudyak S, et al: Cks1-dependent proteasome recruitment and activation of CDC20 transcription in budding yeast. Nature 424: 1009-1013, 2003.

40. Tedesco D, Lukas J and Reed SI: The pRb-related protein p130 is regulated by phosphorylation-dependent proteolysis via the protein-ubiquitin ligase SCF(Skp2). Genes Dev 16: 2946-2957, 2002.

41. Wang W, Ungermannova D, Jin J, et al: Negative regulation of SCFSkp2 ubiquitin ligase by TGF-beta signaling. Oncogene 23: 1064-1075, 2004

42. Foster JS, Fernando RI, Ishida N, et al: Estrogens down-regulate p27Kip1 in breast cancer cells through Skp2 and through nuclear export mediated by the ERK pathway. J Biol Chem 278: 41355-41366, 2003.

43. Signoretti S, Di Marcotullio L, Richardson A, et al: Oncogenic role of the ubiquitin ligase subunit Skp2 in human breast cancer. J Clin Invest 110: 633-641, 2002.

44. Boehm M, Yoshimoto T, Crook MF, et al: A growth factordependent nuclear kinase phosphorylates p27(Kip1) and regulates cell cycle progression. EMBO J 21: 3390-3401, 2002.

45. Viglietto G, Motti ML, Bruni P, et al: Cytoplasmic relocalization and inhibition of the cyclin-dependent kinase inhibitor p27(Kip1) by PKB/Akt-mediated phosphorylation in breast cancer. Nat Med 8: 1136-1144, 2002.

46. Grana X, Garriga J and Mayol X: Role of the retinoblastoma protein family, pRB, p107 and p130 in the negative control of cell growth. Oncogene 17: 3365-3383, 1998.

47. Carroll JS, Prall OW, Musgrove EA and Sutherland RL: A pure estrogen antagonist inhibits cyclin E-Cdk2 activity in MCF-7 breast cancer cells and induces accumulation of p130-E2F4 complexes characteristic of quiescence. J Biol Chem 275: 38221-38229, 2000. 